\title{
ADSORÇÃo DE FENOL SOBRE CARVÃO ATIVADO EM MEIO ALCALINO
}

\author{
Viviane Vasques da Silva Guilarduci, João Paulo de Mesquita, Patrícia Benedini Martelli e Honória de Fátima Gorgulho* \\ Departamento de Ciências Naturais, Universidade Federal de São João del Rei, Campus Dom Bosco, Praça Dom Helvécio, 74, \\ São João del Rei - MG, Brasil
}

Recebido em 27/9/05; aceito em 10/2/06; publicado na web em 14/6/06

\begin{abstract}
PHENOL ADSORPTION ON COMMERCIAL ACTIVE CARBON UNDER ALKALINE CONDITIONS. The present study describes phenol adsorption on commercial active carbon (CAF) under alkaline conditions in the concentration range of 0.01 to $2.08 \mathrm{mmol} \mathrm{L}^{-1}$. Surface characterization has been performed by means of surface area measurements, IR spectroscopy and Boehm titration. The effect of temperature on the adsorption equilibrium isotherm was investigated at $23,30,40,50$ and $60{ }^{\circ} \mathrm{C}$. The results showed that adsorption capacity decreased with increasing temperature. The adsorption kinetics and the role of surface characteristics on the adsorption of phenol also discussed.
\end{abstract}

Keywords: phenol; adsorption; activated carbons.

\section{INTRODUÇÃOO}

A adsorção de compostos orgânicos em carvão ativado (CA) é uma das tecnologias mais importantes utilizada para tratamento de efluentes industriais ${ }^{1,2}$. O CA é um adsorvente microporoso que pode ser obtido de uma variedade de materiais carbonáceos, incluindo madeira, hulha, lignina, casca de coco, açúcares etc ${ }^{3-7}$. Seu poder adsorvente é proveniente da alta área superficial e da presença de uma variedade de grupos funcionais em sua superfície. A estrutura do CA é basicamente constituída por uma base grafítica em que os vértices e as bordas podem acomodar uma série de elementos, como oxigênio, nitrogênio e hidrogênio, que se apresentam como grupos funcionais ${ }^{8}$.

O oxigênio é o principal átomo que aparece na rede de carbono, presente principalmente nos grupos funcionais carbonila, carboxila, hidroxila e enóis. Estes grupos superficiais influenciam a reatividade e as propriedades de adsorção do material. O CA pode ser modificado através de tratamento térmico, oxidação e impregnação com vários compostos orgânicos e inorgânicos ${ }^{9,10}$. Atualmente, a literatura sobre o assunto é concordante de que a sorção de compostos orgânicos em CA é controlada basicamente por interações físicas e químicas, em que tanto os microporos quanto as propriedades ácido-base da superfície tem papel essencial no mecanismo do processo ${ }^{11}$.

Dentre os principais poluentes estudados no processo de sorção em CA estão o fenol e seus derivados. Tem-se estabelecido que a principal forma de interação entre fenol e CA é através da ligação entre os elétrons do sistema- $\pi$, ou seja, os elétrons- $\pi$ do anel aromático do fenol ligam-se ao sistema- $\pi$ das camadas grafíticas do carvão. Essa interação ocorre paralelamente ao plano basal do $\mathrm{CA}^{12}$.

Outra forma de interação estabelecida para a sorção de fenol em CA é a formação de um complexo doador-receptor. Neste tipo de interação os grupos superficiais, em especial a carbonila, interagem com o grupo $\mathrm{OH}$ do fenol. A ligação ocorre com o fenol perpendicular ao plano basal das camadas grafíticas ${ }^{12}$. Esse tipo de ligação tem sido apontado como a principal causa da irreversibilidade do processo de adsorção do fenol em $\mathrm{CA}^{11}$.

*e-mail: gorgulho@ufsj.edu.br
De forma geral, os estudos da adsorção de fenol em CA indicam que não apenas as interações fenol-carvão via ligação $\pi-\pi$ ou formação de complexos doador-receptor controlam o mecanismo de adsorção, mas também a porosidade do carvão e suas propriedades ácido-base. Terzyk ${ }^{13}$, a partir de estudos calorimétricos com amostras de CA em pHs ácido e neutro, demonstrou que a adsorção pela formação do complexo doador-receptor ocorre principalmente na superfície dos meso e microporos, bloqueando a entrada do fenol para os microporos menores. O caráter hidrofílico da superfície dos poros cresce com a presença de grupos ácidos superficiais, o que favoreceria a formação de "clusters" com a água, impedindo a difusão do fenol para dentro dos microporos ${ }^{14}$.

Este mesmo estudo mostrou que a forma das isotermas de adsorção fenol-carvão são afetadas pela faixa de concentração do soluto e heterogeneidade da superfície. Este comportamento é explicado em termos de um mecanismo misto que inclui preenchimento dos microporos e natureza ácido-base da superfície ${ }^{13,14}$. Como os grupos funcionais se concentram nos mesoporos, estes podem interagir com o solvente e dependendo do $\mathrm{pH}$ favorecer ou não a adsorção do fenol para os poros menores.

Apesar da grande quantidade de estudos sobre os fatores que influenciam o processo de adsorção de fenol, seu mecanismo ainda não é completamente entendido ${ }^{11}$. A maioria dos trabalhos tem explorado o mecanismo de adsorção em meios neutro e ácido, que não são os pHs encontrados em muitos efluentes de indústrias têxteis e algumas minerações. Neste sentido, este trabalho teve como objetivo estudar o comportamento da adsorção de fenol em meio básico, usando uma amostra com baixa concentração de sítios ácidos. Desta forma, espera-se que em $\mathrm{pH}$ acima do ponto de carga zero, PCZ, a concentração de grupos ácidos desprotonados seja baixa. Assim, o efeito da interação da superfície grafítica com o solvente deve controlar o processo de carga superficial. Para caracterizar a superfície do CA, empregamos o método tradicional de Boehm ${ }^{15,16}$. Outra estratégia utilizada para estudar o efeito do meio alcalino no processo de adsorção foi a obtenção da adsorção em função da temperatura. De acordo com a literatura, os efeitos dos grupos superficiais tendem a desaparecer com o aumento da temperatura e o mecanismo passa a ser dominado pela média do diâmetro dos poros, que pode sofrer variações de acordo com o grau de interação com o solvente ${ }^{11-14}$. 


\section{PARTE EXPERIMENTAL}

\section{Reagentes}

Esse estudo foi conduzido a partir de CA comercial da Fluka que foi lavado com solução aquosa de $\mathrm{NaOH}$ (Merck) $0,1 \mathrm{~mol} \mathrm{~L}^{-1}$ para retirar impurezas solúveis, como resíduos de ácido húmico etc. Após lavagem com água e posterior secagem em estufa à $100{ }^{\circ} \mathrm{C}$, foi denominado CAF.

Para os procedimentos de titulação, soluções padronizadas de $\mathrm{NaHCO}_{3}$ (Synth), $\mathrm{Na}_{2} \mathrm{CO}_{3}$ (Synth), $\mathrm{NaOH}$ (Merck) e $\mathrm{HCl}$ (Synth) foram preparadas no mesmo dia a partir de água destilada, deionizada e fervida (para eliminar carbonatos).

\section{Análise de fenol}

A análise de fenol foi baseada na metodologia do "Standard Methods for Examination of Water and Wastewater"17. O procedimento baseia-se na ligação oxidativa do fenol com 4-aminoantipirina em meio alcalino, como representado pela Equação:
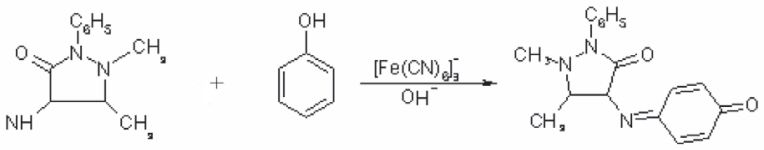

A reação ocorre instantaneamente empregando-se hexaciano ferrato de potássio como oxidante, tendo como produto um complexo marrom-avermelhado, o qual foi medido a $490 \mathrm{~nm}$.

O método foi adaptado para um sistema em fluxo (FIA) por confluência ${ }^{18}$ para a adição dos reagentes, empregando-se um espectrofotômetro FEMTO 435. Curvas analíticas na faixa de 0,01 a $0,12 \mathrm{mmol} \mathrm{L}^{-1}$ foram utilizadas para quantificar a concentração do fenol na solução de equilíbrio das isotermas.

As concentrações dos reagentes usados foram $0,2 \%(\mathrm{~m} / \mathrm{v})$ de 4-aminoantipirina $(\mathrm{pH} 11)$ e $0,1 \%(\mathrm{~m} / \mathrm{v})$ de hexaciano ferrato de potássio em solução tampão de amônia ( $\mathrm{pH} 8,5)$. Para o estudo em meio neutro $(\mathrm{pH} 6)$, prepararam soluções de referência em $\mathrm{H}_{2} \mathrm{O}$, utilizando água como carregadora. Para a avaliação dos outros $\mathrm{pHs}$ $(2,0 ; 10$ e 12$)$, prepararam soluções de referência e carregadora adicionando-se $\mathrm{HCl}$ ou $\mathrm{NaOH}$ (para meio não tamponado). Para o meio tamponado utilizou-se $\mathrm{H}_{3} \mathrm{PO}_{4}$ com $\mathrm{NaHPO}_{4}(\mathrm{pH} 2,0)$ e $\mathrm{NH}_{4} \mathrm{Cl}$ com $\mathrm{NaOH}$ ( $\mathrm{pH} 8,5)$. Dessa forma, o procedimento consistiu em construir curvas analíticas para os diferentes pHs estudados nas isotermas. Este critério foi adotado porque observamos que ocorria interferência nas medidas onde $\mathrm{o} \mathrm{pH}$ não era corrigido.

\section{Construção das isotermas em diferentes pHs}

Para a construção das isotermas foram utilizadas soluções aquosas de fenol na faixa de concentração de 0,010 até $2,08 \mathrm{mmol} \mathrm{L}^{-1}$. O volume total de $100 \mathrm{~mL}$ para cada concentração foi colocado em um erlenmeyer onde se adicionou $0,025 \mathrm{~g}$ de CAF, em seguida o $\mathrm{pH}$ foi ajustado com $\mathrm{NaOH} 0,1 \mathrm{~mol} \mathrm{~L}^{-1}$ e/ou $\mathrm{HCl} 0,1 \mathrm{~mol} \mathrm{~L}^{-1}$. A mistura foi então colocada em uma mesa agitadora onde ficou a $180 \mathrm{rpm}$ durante $24 \mathrm{~h}$. Após esse período, alíquotas de cada amostra foram centrifugadas e levadas para análise da concentração residual de fenol.

\section{Determinação das características ácido-base da superfície}

A metodologia utilizada baseia-se no uso de reações da química orgânica para caracterização dos oxigênios quimiossorvidos na superfície do CA, como grupos carboxílicos, fenólicos e lactonas ${ }^{15,16}$.
Estes grupos reagem com diferentes bases em uma típica reação de neutralização: ácidos carboxílicos podem ser neutralizados pela reação com $\mathrm{NaHCO}_{3}$; ácidos carboxílicos e lactonas são neutralizados com $\mathrm{Na}_{2} \mathrm{CO}_{3}$ e todos estes grupos mais os fenóis podem ser neutralizados por $\mathrm{NaOH}$. O número de sítios com caráter básico pode ser avaliado utilizando-se $\mathrm{HCl}$.

O procedimento consistiu em pesar 0,25 e 0,50 g de CAF que foram colocadas em agitação durante $24 \mathrm{~h}$ com $20 \mathrm{~mL}$ de $\mathrm{NaHCO}_{3}$ (Synth), 0,05 mol L-1, em recipiente selado e com atmosfera de $\mathrm{N}_{2}$. $\mathrm{O}$ mesmo processo foi feito usando os regentes $\mathrm{Na}_{2} \mathrm{CO}_{3}$ (Synth), $\mathrm{NaOH}$ (Merck) e $\mathrm{HCl}$ (Vetec) $\left(0,05 \mathrm{~mol} \mathrm{~L}^{-1}\right)$. Após esse período, uma alíquota foi retirada de cada frasco e titulada com soluções padronizadas de $\mathrm{HCl}$ ou $\mathrm{NaOH}$, para se obter o quanto da base ou do ácido foi neutralizado. A partir destes dados pode-se calcular o número de sítios relacionados ao conjunto de grupos orgânicos de caráter ácido ou básico.

\section{Determinação do ponto de carga zero (PCZ)}

O ponto de carga zero ( $\mathrm{PCZ}$ ) é definido como o $\mathrm{pH}$ em que a superfície do carvão possui carga neutra. A metodologia empregada para sua determinação é denominada "experimento dos 11 pontos", e foi descrita por Regalbuto et al. ${ }^{19}$. O procedimento consistiu em fazer a mistura de $50 \mathrm{mg}$ do CAF em $50 \mathrm{~mL}$ de solução aquosa sob 11 diferentes condições de $\mathrm{pH}$ inicial $(1,2,3,4,5,6,8,9,10,11 \mathrm{e}$ 12) e medir o pH após 24 h de equilíbrio. Fazendo-se o gráfico de $\mathrm{pH}$ final versus $\mathrm{pH}$ inicial, o PCZ corresponde à faixa onde o $\mathrm{pH}$ final se mantém constante independentemente do $\mathrm{pH}$ inicial, ou seja a superfície comporta-se como um tampão.

\section{Medidas de monitoramento de $\mathrm{pH}$ e sorção}

Para estas medidas foram utilizados $50 \mathrm{~mL}$ de água ou solução aquosa de fenol para $0,100 \mathrm{~g}$ de CAF. $\mathrm{O}$ pH da solução foi ajustado com $\mathrm{HCl}$ ou NaOH $0,1 \mathrm{~mol} \mathrm{~L}^{-1}$. Para os procedimentos em solvente tamponado utilizou-se para meio ácido o tampão de $\mathrm{H}_{3} \mathrm{PO}_{4} \mathrm{e}$ $\mathrm{Na}_{2} \mathrm{HPO}_{4}$, e para meio básico tampão de $\mathrm{NH}_{4} \mathrm{Cl}$ e $\mathrm{NaOH}$. O monitoramento do $\mathrm{pH}$ foi feito através de um $\mathrm{pH}$-mêtro Quimis $400 \mathrm{~ms}$, interfaceado por um microcomputador. A sorção de fenol foi acompanhada pela retirada de alíquotas da ordem de 1,0 $\mu \mathrm{L}$ e posterior análise no sistema FIA $^{18}$.

\section{Modelo utilizado no ajuste das isotermas}

As isotermas de adsorção obtidas neste estudo foram ajustadas com os modelos de Langmuir e Langmuir-Freudlich (LF). O modelo de Langmuir define o processo de adsorção em superfícies sólidas como uma reação de associação/dissociação:

$\mathrm{A}+\mathrm{B} \rightleftharpoons \mathrm{AB}$

onde A representa a espécie a ser adsorvida e B, os sítios adsorventes livres presentes na superfície. Para baixas concentrações em um sistema homogêneo verifica-se a relação ${ }^{20}$ :

$[\mathrm{AB}] \propto[\mathrm{A}]$

A equação de Langmuir é dada por:

$q=Q_{L} \frac{K_{L} C}{1+K_{L} C}$

onde q representa a quantidade de material adsorvido em mmol $\mathrm{g}^{-1} ; \mathrm{K}_{\mathrm{L}}$ a constante de Langmuir em $\mathrm{L} \mathrm{mmol}^{-1}$, sendo que essa cons- 
tante é uma medida direta da intensidade de adsorção e, por isso, é também denominada constante de afinidade; $\mathrm{Q}_{\mathrm{L}}$ é a capacidade máxima de adsorção de uma monocamada, em mmol g-1 e $\mathrm{C}$ a concentração de equilíbrio na fase líquida em $\mathrm{mmol} \mathrm{L}^{-1}$.

A isoterma de Langmuir-Freudlich (LF) tem sido aplicada para tratar estudos de adsorção em superfícies heterogêneas, apresentando uma relação exponencial entre o substrato livre (A) e o adsorvido $(\mathrm{AB})^{20,21}$ :

$[\mathrm{AB}] \alpha[\mathrm{A}]^{\alpha}$

onde o expoente $\alpha$ tem valor entre 0 e 1 . Essa relação de potência foi tratada por vários autores de maneira fenomenológica que levou a relacionar o expoente com a distribuição da afinidade na superfície do sorvente. O tratamento matemático foi feito por Sips, que mostrou que esse parâmetro de distribuição se aproxima de uma gaussiana ${ }^{20,21}$. O limite $\alpha=1$ corresponde a um sistema homogêneo, enquanto $\alpha<1$ refere-se ao aumento da heterogeneidade. Sua expressão matemática é dada por:

$\mathrm{q}=\mathrm{Q}_{\mathrm{L}-\mathrm{F}} \frac{\left(\mathrm{K}_{\mathrm{LF}} \mathrm{C}\right)^{\alpha}}{1+\left(\mathrm{K}_{\mathrm{LF}} \mathrm{C}\right)^{\alpha}}$

onde q é a quantidade de material adsorvido ( $\mathrm{mmol} \mathrm{g}^{-1}$ ); $\mathrm{Q}_{\mathrm{L}-\mathrm{F}}$ é a capacidade máxima de adsorção que reflete a área ocupada por uma monocamada de adsorvente ( $\mathrm{mmol} \mathrm{g}^{-1}$ ); $\mathrm{C}$ é a concentração de equilíbrio na fase líquida em $\mathrm{mmol} \mathrm{L}^{-1} ; \mathrm{K}_{\mathrm{LF}}$ é a constante em $\mathrm{L}$ mmol ${ }^{-1}$, que relaciona a média da afinidade do ligante pela superfície e $\alpha$ é o índice de heterogeneidade, que varia de 0 até 1 . A isoterma LF tem sido usada com sucesso para modelar o comportamento da adsorção em superfícies heterogêneas, incluindo a adsorção de inorgânicos e orgânicos em $\mathrm{CA}^{21}$.

Neste trabalho utilizamos o programa Origin 6.1 para obter o ajuste dos dados experimentais aos modelos das Equações 3 e 5.

\section{Análise de área superficial e porosidade}

Os valores de área superficial específica e porosidade foram determinados a partir de isotermas de adsorção de $\mathrm{N}_{2}$ a $77 \mathrm{~K}$ usando um equipamento NOVA 300 BET analisador da Quanta Chrome, USA. Os valores de área e tamanho médio de poro foram obtidos a partir da aplicação dos modelos de BET e BJH para os dados da isoterma.

\section{Análise de espectroscopia vibracional no infra-vermelho}

Os espectros na região do infra-vermelho foram feitos em equipamento Perkin-Elmer 1720 FTIR spectrometer - na faixa de 350 até $4000 \mathrm{~cm}^{-1}$. A amostra de CAF em pó foi diluída em $\mathrm{KBr}$ (Merck, para espectroscopia) na razão de aproximadamente 1/500. A mistura foi prensada em vácuo e a pastilha resultante foi seca em estufa por $20 \mathrm{~h}$. Os espectros foram medidos com acumulação de 60 varreduras e resolução de 4 e $8 \mathrm{~cm}^{-1}$. Como a resolução de $4 \mathrm{~cm}^{-1}$ apresentou muito ruído em relação à de $8 \mathrm{~cm}^{-1}$, optou-se pela última condição para estudos posteriores.

\section{RESULTADOS E DISCUSSÃO}

\section{Área superficial e porosidade}

A partir da isoterma BET de adsorção e dessorção de $\mathrm{N}_{2}$, obtivemos para o CAF área superficial de $717 \mathrm{~m}^{2} / \mathrm{g}$ e diâmetro médio de $34 \mathrm{~nm}$. A análise da distribuição do volume de poros em função do diâmetro indicou que o CAF é principalmente caracterizado por mesoporos $(2-50 \mathrm{~nm})$.

\section{Caracterização ácido-base da superfície do CAF}

Os resultados obtidos da titulação de Boehm e o valor do PCZ estão apresentados na Tabela 1.

Os resultados da Tabela 1 mostram que a superfície do CAF não se caracteriza por grupos ácidos fortes como os carboxílicos, mas especialmente por grupos fenólicos e lactonas. Praticamente não foram detectados sítios ácidos para a faixa de $\mathrm{pKa}<5,0$ (ácidos carboxílicos) e apenas 7,5\% do total de centros ácidos correspondem à faixa de pKa de lactonas. Ou seja, 92,5\% dos sítios ácidos referemse à faixa de pKa do fenol. Os grupos fenólicos são extremamente fracos e sua desprotonação ocorre apenas em $\mathrm{pH}$ maior que $\approx 10$.

A concentração total de sítios básicos, $0,30 \mathrm{mmol} \mathrm{g}^{-1}$, reflete a contribuição dos planos grafíticos para o comportamento ácido base da superfície.

De forma geral, esses resultados são concordantes com uma superfície anfótera, $\mathrm{PCZ} \approx 6,5$, em que grupos ácidos e básicos são afetados igualmente pelo $\mathrm{pH}$ do meio.

\section{Espectroscopia de infra-vermelho}

No espectro de infravermelho do CAF, Figura 1, foi possível distinguir duas regiões importantes, a primeira situada entre 4000 até $2500 \mathrm{~cm}^{-1}$, e a segunda na faixa de menor freqüência, abaixo de $1800 \mathrm{~cm}^{-1}$. Em $3430 \mathrm{~cm}^{-1}$ observa-se uma banda de absorção típica de $\delta(\mathrm{OH})$, que normalmente também está associada à presença de ligação hidrogênio. Essa absorção foi atribuída à presença predominantemente de grupos $\mathrm{OH}$ de fenóis pois, em geral, a presença significativa de $\delta(\mathrm{OH})$ de grupos carboxílicos em CA se caracteriza por forte absorção, que se estende até $2500 \mathrm{~cm}^{-1}$. As absorções localizadas na região de 2960 até $2845 \mathrm{~cm}^{-1}$ são características de vibrações simétricas e assimétricas de grupos metilas e metilenos ${ }^{22}$.

A região de 1800 até $1600 \mathrm{~cm}^{-1}$ do espectro é onde normalmente se observa a sobreposição de várias bandas de absorção, que podem ser deslocadas para valores menores de comprimento de onda. Podese identificar o pico localizado em $1576 \mathrm{~cm}^{-1}$, que é característico do estiramento da ligação $\mathrm{C}=\mathrm{C}$ de grupos aromáticos ${ }^{23}$. A absorção situada em $1738 \mathrm{~cm}^{-1}$, é característica do estiramento de carbonila $\delta(\mathrm{C}=\mathrm{O})$, que juntamente com vibração de deformação axial da ligação C-O, que aparece como um ombro em $1165 \mathrm{~cm}^{-1}$, podem sugerir a presença tanto de ácidos carboxílicos como de ésteres ou $\delta$-lactonas ligados a grupos aromáticos. No caso de ácidos carboxílicos, a banda de carbonila é mais intensa, portanto deduzimos que este grupo funcional não está presente em quantidades apreciáveis no CAF.

$\mathrm{Na}$ faixa de 1390 até $1000 \mathrm{~cm}^{-1}$ podemos observar bandas relacionadas à ligação $\mathrm{C}-\mathrm{O}-\mathrm{H}$, referentes às vibrações axial $\mathrm{v}(\mathrm{C}-\mathrm{O}) \mathrm{e}$

Tabela 1. Resultados da análise dos sítios ácidos e básicos de acordo com o método de Boehm

\begin{tabular}{lcccc}
\hline $\begin{array}{l}\text { Ácidos carboxílicos } \\
\mathrm{mmol} \mathrm{g}^{-1}\end{array}$ & $\begin{array}{c}\text { Lactonas } \\
\mathrm{mmol} \mathrm{g}{ }^{-1}\end{array}$ & $\begin{array}{c}\text { Fenólicos } \\
\mathrm{mmol} \mathrm{g}\end{array}$ & $\begin{array}{c}\text { Total sítios ácidos } \\
\mathrm{mmol} \mathrm{g}^{-1}\end{array}$ & $\begin{array}{c}\text { Total sítios básicos } \\
\mathrm{mmol} \mathrm{g}^{-1}\end{array}$ \\
\hline $0,00 \pm 0,01$ & $0,03 \pm 0,01$ & $0,37 \pm 0,05$ & $0,40 \pm 0,05$ & $0,30 \pm 0,05$ \\
\hline
\end{tabular}



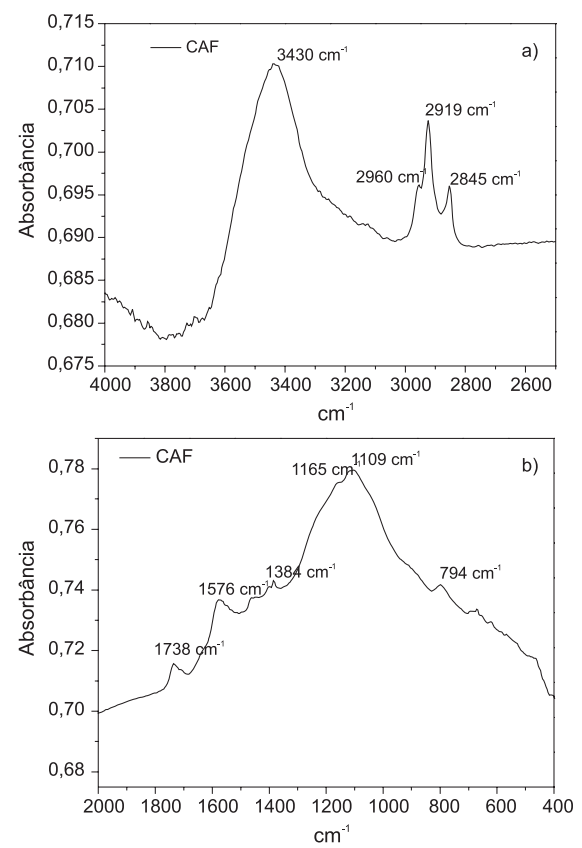

Figura 1. Espectro de infravermelho do CAF: a) faixa de 4000 até $2600 \mathrm{~cm}^{-1}$, b) faixa de 2000 até $400 \mathrm{~cm}^{-1}$

angular $v(\mathrm{OH})$. A absorção em $1384 \mathrm{~cm}^{-1}$ tem sido observada para pastilhas de fenóis, que resulta das interações entre as vibrações $v(\mathrm{C}-\mathrm{O})$ e $\mathrm{v}(\mathrm{OH})$. Estas absorções podem confirmar a presença de estruturas fenólicas ${ }^{22}$. A presença de aromáticos com substituição no anel são responsáveis pelas absorções entre 830 e $672 \mathrm{~cm}^{-1}$.

Os resultados desta análise são concordantes com os obtidos da titulação de Boehm, onde grupos fenólicos foram identificados e praticamente não se observou presença significativa de ácidos carboxílicos.

\section{Isotermas de adsorção}

Pode-se obter um panorama do comportamento do processo de adsorção de fenol no CAF através das isotermas de adsorção obtidas para os pHs 2, 6, 10 e 12, mostradas na Figura 2. Nota-se que a adsorção é favorecida pelo aumento do $\mathrm{pH}$ até 10 , enquanto que para $\mathrm{pH} 12$ ocorre uma queda significativa de q, observada especialmente após a concentração de aproximadamente $0,2 \mathrm{mmol} \mathrm{L}^{-1}$.

Comportamento semelhante ao mostrado na Figura 2 foi observado por outros autores e tem sido explicado com base nos efeitos da carga superficial do CA na interação com o fenol em meio aquoso $^{11}$. Tanto as interações $\pi-\pi$ como a formação de complexos tipo doador-receptor entre o fenol e o CA podem ser afetadas pelas cargas superficiais. Em pH abaixo do PCZ, cargas positivas vão se formando na superfície devido à protonação dos grupos básicos e ácidos, enfraquecendo as interações com o substrato e aumentando a afinidade com o solvente. Ou seja, para o CAF além da base grafítica também os grupos fenólicos e lactonas, identificados pela

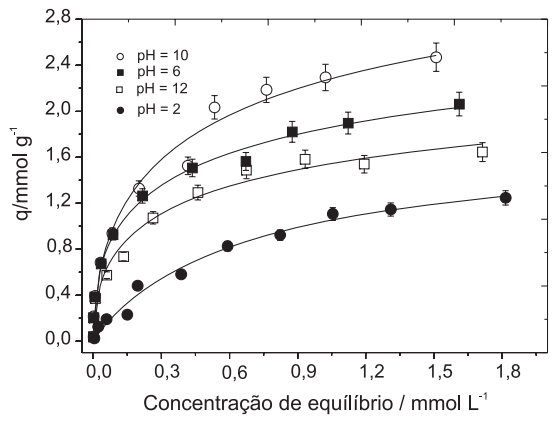

Figura 2. Isotermas de adsorção do fenol em CAF como função da concentração de equilíbrio, para diferentes $p H s$. Pontos indicam resultados experimentais e as linhas, o ajuste feito pelo modelo Langmuir-Freudlich, Equação 5

titulação de Boehm e IV, encontram-se protonados em $\mathrm{pH}<\mathrm{PCZ}$, aumentando o caráter hidrofílico da superfície.

Com o aumento do $\mathrm{pH}$, os grupos básicos e ácidos da superfície do CAF vão se tornando ionizados e ficam disponíveis para formar complexos do tipo doador-receptor com o carvão. Inicialmente, os grupos lactonas se hidrolisam $(\mathrm{pH} \approx 7,0)$ e, em seguida, os grupos fenólicos se ionizam $(\mathrm{pH} \approx 10)$. O plano basal é desprotonado para valores maiores que o PCZ, liberando sítios para a ligação $\pi-\pi$ entre fenol e CAF.

Para valores muito altos de $\mathrm{pH}$ o excesso de carga negativa na superfície acarreta na repulsão com o íon fenolato. Além disso, nesta faixa de $\mathrm{pH}$ a interação do íon fenolato com o solvente é maior que com a superfície. Como consequiência, temos a diminuição da adsorção de fenol pelo CAF em pH 12. Deve-se observar que estes efeitos de repulsão se tornam mais importantes após a concentração de aproximadamente $0,2 \mathrm{mmol} \mathrm{L}^{-1}$ onde, provavelmente, a superfície já não consegue dispersar os efeitos de carga.

Os dados experimentais das isotermas foram ajustados com as Equações Langmuir-Freudlich (LF) (Equação 5) e de Langmuir (Equação 3). Na Figura 4, as linhas que ligam os pontos representam a isoterma LF. Os parâmetros obtidos pelos ajustes estão resumidos na Tabela 2.

O parâmetro $\alpha$ (obtido da isoterma LF) é normalmente relacionado à distribuição da energia de adsorção nos poros, ou seja, seu valor diminui com o aumento da heterogeneidade na superfície. Terzyk $^{13,14}$ demostrou que em $\mathrm{pH}$ neutro e ácido existe relação entre tamanho dos poros e adsorção. Em meio ácido os poros se comportam como sendo menores, obtendo maiores valores de $\alpha$. Esse comportamento é explicado pela afinidade dos grupos ácidos superficiais com o solvente, a água, formando "clusters" de $\mathrm{H}_{2} \mathrm{O}$ que atuam como bloqueadores para entrada de fenol. Nossos resultados são concordantes com estes estudos, pois pela Tabela 2 podemos observar que em $\mathrm{pH}$ 2,0 o valor de $\alpha$ é maior (menor volume de poros), correspondendo a um valor menor de $Q_{L F}$. Com o aumento do $\mathrm{pH}$, o valor de $\alpha$ diminui quase pela metade, indicando maior heterogeneidade da superfície (maior volume de poros). Em meio básico

Tabela 2. Resultados do ajuste das isotermas (Figura 2) ao modelo de Langmuir-Freudlich e Langmuir

\begin{tabular}{lccccccc}
\hline $\mathrm{pH}$ & $\mathrm{KL}_{\mathrm{LF}} \mathrm{L} \mathrm{mmol}^{-1}$ & $\alpha$ & $\mathrm{Q}_{\mathrm{LF}} \mathrm{mmol} \mathrm{g}^{-1}$ & $\mathrm{R}_{\mathrm{LF}}^{2}$ & $\mathrm{~K}_{\mathrm{L}} \mathrm{L} \mathrm{mmol}^{-1}$ & $\mathrm{Q}_{\mathrm{L}} \mathrm{mmol} \mathrm{g}^{-1}$ & $R_{L}$ \\
\hline 2 & $1,105 \pm 0,686$ & $0,949 \pm 0,062$ & $1,966 \pm 0,399$ & 0,99 & $1,528 \pm 0,160$ & $1,713 \pm 0,123$ & 0,96 \\
6 & $1,395 \pm 1,314$ & $0,489 \pm 0,065$ & $3,297 \pm 0,574$ & 0,98 & $7,498 \pm 1,256$ & $1,980 \pm 0,106$ & 0,97 \\
10 & $1,049 \pm 1,384$ & $0,520 \pm 0,067$ & $4,568 \pm 1,089$ & 0,99 & $5,998 \pm 0,681$ & $2,610 \pm 0,155$ \\
12 & $1,225 \pm 1,083$ & $0,557 \pm 0,012$ & $2,728 \pm 0,467$ & 0,99 & $4,578 \pm 0,994$ & $1,772 \pm 0,102$ & 0,98 \\
\hline
\end{tabular}


esse valor é praticamente constante, o que concorda com o pressuposto de que no processo de adsorção em meio alcalino a interação do CAF com o solvente é menor e o processo seria mais afetado pela repulsão entre as cargas.

Os valores de $\mathrm{K}_{\mathrm{LF}}$ e $\mathrm{K}_{\mathrm{L}}$ mostrados na Tabela 2 são concordantes com uma fraca interação entre fenol e superfície do CAF, que é característica das interações de fenol com CA, as quais são principalmente de natureza dispersiva (forças de London). Maiores valores de $\mathrm{K}_{\mathrm{LF}}$ são observados para substâncias fenólicas contendo grupos funcionais que favorecem a interação química com a superfície, como por ex., o 2,3,4-triclorofenol em que o $\mathrm{K}_{\mathrm{LF}}$ é da ordem de $18 \mathrm{~L}$ $\mathrm{mmol}^{-1}$ em pH 3,0 e de $51 \mathrm{~L} \mathrm{mmol}^{-1}$ para $\mathrm{pH} 11^{11}$. O valor de $\mathrm{K}_{\mathrm{LF}}$ representa uma média da afinidade do substrato com o sorvente, por isso esse parâmetro não mostra, a princípio, dependência com o pH. Observa-se um grande desvio padrão para este parâmetro, o qual aumenta com o pH. Esse comportamento está relacionado com a heterogeneidade da superfície, que leva a uma dispersão maior nos valores da afinidade. Por outro lado, a constante de Langmuir, $\mathrm{K}_{\mathrm{L}}$, tende a ser crescente com a capacidade de adsorção da monocamada, indicando que a afinidade do CAF com o fenol é maior em pH 6,0 e 10.

No caso da isoterma em pH 10, o CAF ainda não se caracteriza por uma superfície com excesso de carga negativa, podendo apresentar alguns grupos não dissociados, como os fenólicos, e outros desprotonados como as lactonas. A presença de grupos básicos na superfície do CA tem sido considerada como um fator favorável para incrementar a adsorção de fenol ${ }^{24}$. Grupos oxigenados na superfície podem favorecer a adsorção, pela formação de ligação hidrogênio com o fenol. Além disso, em pH 10 grupos fenólicos ionizados compensam um provável excesso de carga negativa através da ressonância com o plano basal do CAF. Essa distribuição de cargas favorece a adsorção do fenol nesse $\mathrm{pH}$, que é verificada pelo maior valor para a capacidade da monocamada $\left(\mathrm{Q}_{\mathrm{LF}}\right.$ e $\left.\mathrm{Q}_{\mathrm{L}}\right)$ e maior valor de $\mathrm{K}_{\mathrm{L}}$.

\section{Efeito da temperatura nas isotermas de adsorção em $\mathbf{p H} 10$}

A maior capacidade de adsorção observada em pH 10 para as isotermas foi discutida em termos da presença dos grupos básicos na superfície, e também, das interações com o plano basal do CAF. Por outro lado, o efeito da difusão do fenol através dos poros do CAF é também determinante no processo. Dessa forma, como a adsorção de fenol em CA envolve preliminarmente os sítios da superfície e depois os microporos, os grupos superficiais podem atuar favorecendo ou não a difusão para os microporos.

Em uma tentativa para avaliar o efeito da superfície na difusão do fenol para os microporos em pH 10, as medidas de adsorção foram realizadas para 5 diferentes temperaturas (de 23 a $60^{\circ} \mathrm{C}$ ). Sabe-se que o processo de adsorção é exotérmico e por isso, deve diminuir com o aumento da temperatura ${ }^{16}$. Por outro lado, o aumento da temperatura também tem o efeito de minimizar a ação dos grupos funcionais da superfície na adsorção, fazendo com que o processo seja controlado pela difusão através dos poros. Dependendo da intensidade com que a adsorção seja afetada por pequenos acréscimos da temperatura, poderemos avaliar a importância da superfície no processo.

As isotermas obtidas em $\mathrm{pH} 10$ foram ajustadas com os modelos de Langmuir-Freudlich e de Langmuir. Os resultados estão representados na Figura 3 e na Tabela 3.

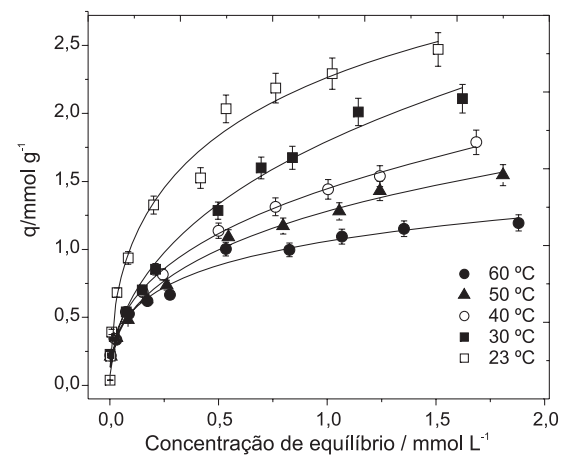

Figura 3. Isotermas de adsorção de fenol em $C A F, p H=10$, para diferentes temperaturas. Pontos indicam resultados experimentais e as linhas, o ajuste feito pelo modelo Langmuir-Freudlich, Equação 5

Podemos observar que o aumento da temperatura de 23 para 30 ${ }^{\circ} \mathrm{C}$ leva a um decréscimo na capacidade máxima de adsorção de $\approx$ $15 \%$, avaliado pelos dois modelos de isotermas. Para a variação de 23 até $60{ }^{\circ} \mathrm{C}$, o decréscimo foi de $\approx 40 \%$. Ou seja, ocorre uma queda na capacidade de adsorção mais brusca para os primeiros aumentos de temperatura. Deve-se observar que os valores de $\mathrm{K}_{\mathrm{L}} \mathrm{e}$ $\mathrm{K}_{\mathrm{LF}}$ decrescem com a temperatura, como esperado para um processo exotérmico. Entretanto essa queda foi mais sensível para a primeira variação de temperatura, o que pode ser conseqüência da desativação das interações da superfície (através de seus grupos funcionais) com o fenol.

$\mathrm{O}$ valor de $\alpha$ também diminui com o aumento da temperatura, mostrando que a superfície se torna mais heterogênea (maior volume de poros). Como a água (mais polar que o fenol) é preferencialmente adsorvida no CAF por ligação hidrogênio com os sítios polares, com o aumento da temperatura essa interação diminui e os poros ficam mais livres para adsorção do fenol. Apesar disso, o CAF foi caracterizado principalmente pela presença de grupos ácidos fracos (fenóis) e pelo número significativo de sítios básicos, o que favorece principalmente a adsorção do fenol com a superfície através das interações de natureza dispersiva (interações $\pi-\pi$ ). Com o aumento da temperatura estas interações são menos estáveis, ao mesmo tempo em que aumenta a afinidade do solvente $\left(\mathrm{H}_{2} \mathrm{O}\right)$ com o fenol.

Para confirmar a natureza das interações fenol-CAF, o valor da entalpia de adsorção foi estimado através da equação de van't Hoff, utilizando-se os valores de $\mathrm{K}_{\mathrm{L}}$ :

$\frac{\mathrm{d}(\ln \mathrm{K})}{\mathrm{d}(1 / \mathrm{T})}=-\frac{\Delta \mathrm{H}_{\mathrm{ad}}}{\mathrm{R}}$

Tabela 3. Resultados do ajuste das isotermas obtidas em pH 10 (Figura 3) ao modelo de Langmuir e Langmuir-Freudlich

\begin{tabular}{|c|c|c|c|c|c|c|c|}
\hline $\mathrm{T} / \mathrm{K}$ & $\mathrm{K}_{\mathrm{L}} \mathrm{mmol} \mathrm{L}^{-1}$ & $\mathrm{Q}_{\mathrm{L}} \mathrm{mmol} \mathrm{g}^{-1}$ & $\mathrm{R}_{\mathrm{L}}^{2}$ & $\mathrm{~K}_{\mathrm{LF}} \mathrm{L} \mathrm{mmol}^{-1}$ & $\alpha$ & $\mathrm{Q}_{-\mathrm{F}} \mathrm{mmol} \mathrm{g}{ }^{-1}$ & $\mathrm{R}_{\mathrm{LF}}^{2}$ \\
\hline 296,15 & $5,998 \pm 0,663$ & $2,610 \pm 0,186$ & 0,98 & $1,049 \pm 1,384$ & $0,520 \pm 0,067$ & $4,568 \pm 1,089$ & 0,99 \\
\hline 303,15 & $3,998 \pm 0,958$ & $2,216 \pm 0,113$ & 0,97 & $0,756 \pm 0,532$ & $0,663 \pm 0,121$ & $3,896 \pm 1,155$ & 0,98 \\
\hline 313,15 & $3,622 \pm 0,985$ & $1,895 \pm 0,158$ & 0,97 & $0,517 \pm 0,411$ & $0,529 \pm 0,105$ & $3,521 \pm 1,035$ & 0,99 \\
\hline 323,15 & $3,015 \pm 0,796$ & $1,758 \pm 0,148$ & 0,97 & $0,582 \pm 0,380$ & $0,540 \pm 0,102$ & $3,060 \pm 0,916$ & 0,98 \\
\hline 333,15 & $2,501 \pm 1,040$ & $1,575 \pm 0,220$ & 0,96 & $0,375 \pm 0,416$ & $0,4159 \pm 0,101$ & $2,653 \pm 1,098$ & 0,98 \\
\hline
\end{tabular}


O gráfico obtido para ln K por 1/T está representado na Figura 4.

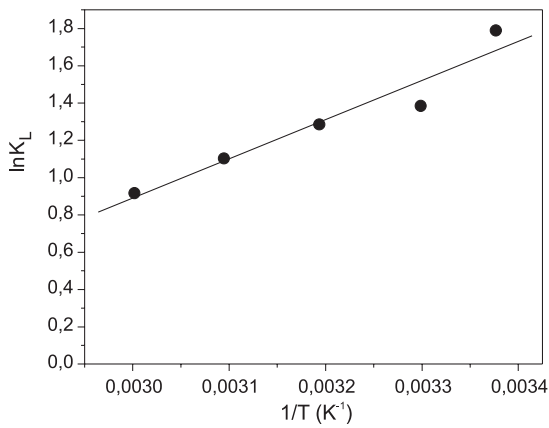

Figura 4. Curva de $\ln K_{L}$ versus $1 / T$ para obtenção do $\Delta H$.

O valor obtido foi de $-17,50( \pm 2,78) \mathrm{Kj} / \mathrm{mol}$ que é da ordem de uma adsorção física, ou seja, de interações do tipo dispersivas (forças de London) que caracterizam o processo de adsorção do fenol no CAF. Este resultado está de acordo com as discussões anteri-ores, demonstrando que a difusão para os microporos é também função das interações dos grupos superficiais do CAF com o fenol em $\mathrm{pH} 10$.

\section{Efeito do solvente no processo de adsorção do fenol no CAF}

Em processos de adsorção é bem conhecida a existência de competição entre solvente e substrato pela superfície do CA. O comportamento do CAF em água mostrou que o mesmo entra em equilíbrio com o meio em $\mathrm{pH}$ próximo do $\mathrm{PCZ}$. O equilíbrio do CA com a água envolve principalmente protonação dos sítios básicos da camada grafítica $^{25}$ :

$\mathrm{C}_{\pi}+2 \mathrm{H}_{2} \mathrm{O} \rightleftharpoons \mathrm{C}_{\pi} \mathrm{H}_{3} \mathrm{O}^{+}+\mathrm{OH}^{-}$

equilíbrio 1

onde $\mathrm{C}_{\pi}$ representa os sítios superficiais que atuam como base de Lewis no CA. Dependendo da natureza do CA esse equilíbrio estará deslocado para uma determinada posição do equilíbrio 1 .

$\mathrm{O}$ fenol $(\phi-\mathrm{OH})$ em meio aquoso comporta-se como um ácido fraco :

$\phi-\mathrm{OH}+\mathrm{H}_{2} \mathrm{O} \rightleftharpoons \phi-\mathrm{O}^{-}+\mathrm{H}_{3} \mathrm{O}^{+} \quad \mathrm{pKa}=9,89 \quad$ equilíbrio 2

o qual em meio alcalino estará deslocado para a forma ionizada.

Quando CAF é colocado em contato com a solução de fenol outro equilíbrio passa a existir, o das espécies do substrato com o solvente $\left(\mathrm{H}_{2} \mathrm{O}\right)$. Os equilíbrios existentes no meio aquoso e a dupla camada elétrica formada na superfície do CAF estão sujeitos ao $\mathrm{pH}$ do meio e às características ácido-base da superfície. Podemos observar o efeito desses equilíbrios neste processo acompanhando a sorção de fenol em meio alcalino tamponado e não tamponado, Figuras $5 \mathrm{a}$ e $\mathrm{b}$.

Em $\mathrm{pH} \approx 10,5$ os grupos fenólicos da superfície do CAF estão parcialmente dissociados e, assim, a camada grafítica estará com sítios superficiais neutros ou negativamente carregados. O excesso de carga negativa é compensado tanto pela ressonância com a camada grafítica quanto pela interação com os íons $\mathrm{H}_{3} \mathrm{O}^{+}$, de acordo com o equilíbrio 1 . Nesta faixa de $\mathrm{pH}$ existe maior interação entre solvente e substrato formando complexos tipo fenol-água ${ }^{26}$, os quais devem ser primeiramente rompidos para que a adsorção ocorra. Neste caso, os íons presentes no tampão amoniacal poderiam também atuar facilitando a quebra deste complexo. Simultaneamente, o processo de adsorção do fenol na superfície do CAF vai envolver o
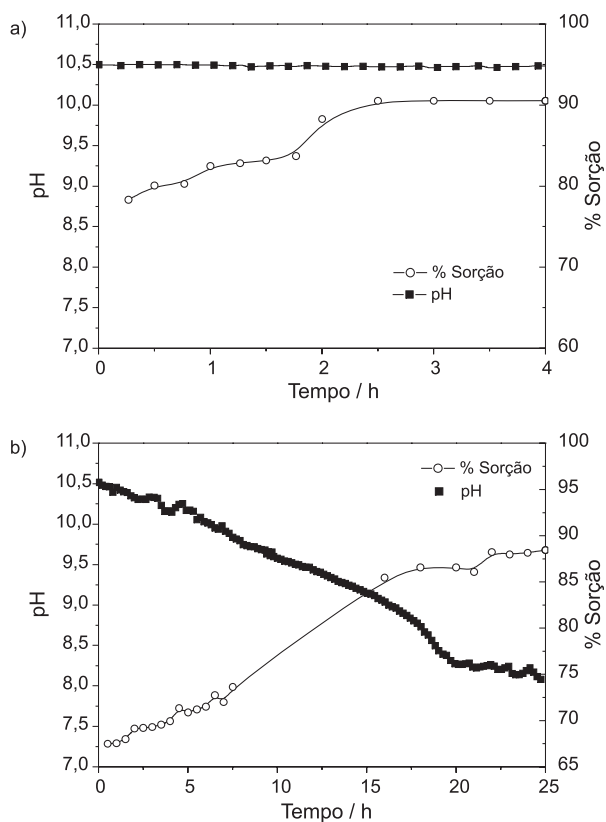

Figura 5. a)- sorção de fenol em meio tamponado. $p H \approx 10,5$. b) sorção de fenol em meio não tamponado. pH inicial igual a 10,5

deslocamento do equilíbrio 1 , no sentido de diminuir o $\mathrm{pH}$. As espécies envolvidas neste equilíbrio em meio tamponado deslocam-se mais facilmente favorecendo a adsorção do fenol, como observado na Figura 5a. Por outro lado, verifica-se que a sorção no CAF em solvente não tamponado, Figura 5b, é mais lenta e o $\mathrm{pH}$ diminui paralelamente como conseqüência do deslocamento dos equilíbrios para manter a neutralidade do meio.

Em meio tamponado ( $\mathrm{pH}$ 10) os equilíbrios das espécies ionizadas são alcançados rapidamente e a sorção atinge $90 \% \mathrm{em}$ aproximadamente $2 \mathrm{~h}$. No caso da sorção em meio sem tampão, somente após $20 \mathrm{~h}$ em equilíbrio a capacidade atinge $90 \%$.

\section{CONSIDERAÇÕES FINAIS}

Os resultados mostraram que a superfície do CAF se caracteriza especialmente por grupos fenólicos e concentração proporcional de centros básicos, o que é concordante com uma superfície anfótera, $\mathrm{PCZ}=6,5$. Estas características se mostraram importantes para a adsorção do fenol em meio alcalino, pois com o aumento da temperatura observou-se um decréscimo da atividade do CAF. O valor do $\Delta \mathrm{H}$ de adsorção obtido mostrou que as interações entre fenol e CAF são principalmente de natureza dispersiva (forças de London) que, em pH 6,0 até 10, podem estar sendo favorecidas pela contribuição dos grupos desprotonados através do efeito de ressonância. Além disso, deve-se acrescentar que o CAF possui grande concentração de mesoporos, onde o processo de adsorção do fenol é especialmente afetado pela funcionalização da superfície, a qual favorece a afinidade com o substrato.

Verificou-se também que os equilíbrios envolvidos durante o processo de sorção em meio alcalino afetam a cinética de reação, mas não alteram a capacidade de adsorção máxima obtida após equilíbrio.

\section{AGRADECIMENTOS}

À FINEP- Financiadora de Estudos e Projetos -Ministério da Ciência e Tecnologia (projeto 01.03.0310.00), CNPq (bolsa de iniciação científica) e ao CDTN- CT1- Belo Horizonte- MG. 


\section{REFERÊNCIAS}

1. Nagano, S.; Tamon, H.; Adzumi, T.; Nakagawa, K.; Suzuki, T.; Carbon 2000, 38, 915 .

2. Juang, R.; Wu, F.; Tseng, R.; Colloids Surf., A 2002, 201, 191.

3. Baçaoui, A.; Yaacoubi, A.; Dahbi, A.; Bennouna, C.; Tan Luu, R. P.; Maldonado-Hodar, F. J.; Utrilla, J. R.; Castilla, C.M.; Carbon 2001, 39, 425.

4. Daguerre, E.; Guillot, A.; Py, X.; Carbon 2000, 38, 59.

5. Daguerre, E.; Guillot, A.; Stoeckli, F.; Carbon 2001, 39, 1279.

6. Nouri, S.; Haghseresht, F.; Adsorption 2004, 10, 79.

7. Garcia, F. S.; Alonso, A. M.; Tascón, J. M. D.; Carbon 2001, 39, 1103.

8. Snoeyink, V. L.; Weber, W. J.; Environ. Sci. Technol. 1967, 1, 228.

9. Figueiredo, J. L.; Pereira, M. F. R.; Freitas, M. M. A.; Órfão, J. J. M.; Carbon 1999, 37, 1379.

10. Chen, J. P.; Shunnian, W.; Chong, K.; Carbon 2003, 41, 1979.

11. Dabrowski, A.; Podkoscielny, P.; Hubicki, Z.; Barczak, M.; Chemosphere 2005, 58, 1049.

12. Nevskaia, M. D.; Lopez, E. C.; Ruiz, A. G.; Environ. Sci. Technol. 2004, 38, 5786.

13. Terzyk, A. P.; J. Colloid Interface Sci. 2004, 275, 9.
14. Terzyk, A. P.; J. Colloid Interface Sci. 2003, 268, 301.

15. Boehm, H. P.; Carbon 1994, 32, 759.

16. Kinoshita, K.; Carbon, Electrochemical and Physicochemical Properties, John Wiley \& Sons: New York, 1988.

17. Eaton, A. D.; Clesceri, L.S.; Greenberg, A. E.; Standard methods for the examination of water and wastewater, $19^{\text {th }}$ ed., American Public Health Association, American Water Works Association and Water Environment Federation: Washington, 1995.

18. Lupetti, K. O; Rocha, F. R. P.; Fatibello Filho, O.; Talanta 2004, 62, 463

19. Regalbuto, J. R.; Robles, J.; The engineering of Pt/Carbon Catalyst Preparation, University of Illinois: Chicago, 2004.

20. Selinger, J. V.; Rabbany, S. V.; Anal. Chem. 1997, 69, 170.

21. Chuncai, Y.; Sep. Purif. Technol. 2000, 19, 237.

22. Podkoscielny, P.; Dabrowski, A., Marijuk, O. V.; Appl. Surf. Sci. 2003, 205, 297.

23. Silverstein, R. M; Bassler, G. C.; Morrill, T. C.; Identificação espectrofotométrica de compostos orgânicos, $5^{\mathrm{a}}$ ed., Guanabara Koogan: Rio de Janeiro, 1994.

24. Serrano, V. G.; Almeida, F. P.; Villegas, P. J.; Carbon 1999, 37, 1517.

25. Leon, C. A.; Solar, J. M.; Calemma, V.; Radovic, L. R.; Carbon 1992, 30, 797.

26. Yamamoto, N.; Shida, N.; Miyoshi, E.; Chem. Phy. Lett. 2003, 371, 724. 